\title{
Surgical Options for the Management of Congestive Heart Failure
}

Congestive heart failure (CHF) continues to be recognized as the most common killer worldwide, and remains the most important medical condition affecting the world today. It is a syndrome that is the end product of heart conditions of different etiologies. CHF is becoming more prevalent as the population continues to age. Populationbased studies from North America and Europe have estimated the prevalence of CHF at about 10-20/1,000 population and the incidence at about 2-3/1,000 population [1]. These figures become quite alarming when extrapolated to the 6,216 million world population at large. About 62-124 million people worldwide suffer from CHF and there are about 12.5-18.6 million new cases each year. It is surmised that an increase in the overall prevalence of $\mathrm{CHF}$ is expected worldwide as a result of the advances in the early detection and treatment of coronary artery disease and the improving survival following acute myocardial infarction as well as the overall increased longevity in the developed countries. The disease is fatal in the long term, as about $60 \%$ of the patients affected die by 5 years from the time of diagnosis. In the developed countries, the cost of management of CHF is estimated to constitute about $2 \%$ of the total health care expenditure worldwide, with $60-70 \%$ of that being spent on hospitalizations. This figure is much less dramatic among developing or underdeveloped countries, which have a limited health care expenditure budget and nonabundance of hospitals and tertiary care centers to treat these patients.

Several advances in medical therapy, with the introduction of angiotensin-converting enzyme inhibitors, selective beta-blockers, type III antiarrhythmic agents, natriuretic peptides and lipid therapy as well as the liberal use of pacemakers and internal defibrillators, have improved the survival of patients suffering from CHF. However, despite all the advances in medical therapy and despite early recognition, the outcome of CHF remains poor. This has prompted investigators to consider newer surgical options for the management of CHF. The small number of heart transplants performed worldwide (between 3,500 and 4,500 transplants annually) makes heart transplantation a limited option that is only available to a privileged section of the world population, primarily confined to developed countries. Over $95 \%$ of the heart transplants performed worldwide are performed in North America and Europe, while less than 5\% are performed in the three heavily populated continents, namely Asia, Africa and South America, where over $75 \%$ of the world population lives.

In view of these limitations, several surgical alternatives for the treatment of CHF are being investigated with the aim of improving the quality of life of these patients in the short term, and also improving the long-term outcome. It has been almost 4 decades since the first experiments with the development of mechanical assist devices to replace the human heart. Ever since, several world centers and investigators have become involved and numerous devices have been developed, although many of them have faded into the past.

This issue of Cardiology is the result of the generous contribution of a select cast of investigators and experts in the surgical management of CHF from premier centers who were invited to participate and kindly accepted. Drs. John Byrne, Lawrence Cohn and associates from the Brigham and Women's Hospital in Boston discuss the

\begin{tabular}{ll}
\hline KARGER & ( ) 2004 S. Karger AG, Basel \\
0008-6312/04/1013-0005\$21.00/0 \\
$\begin{array}{l}\text { Fax +4161306 12 34 } \\
\begin{array}{l}\text { E-Mail karger@karger.ch } \\
\text { www.karger.com }\end{array}\end{array}$ & $\begin{array}{l}\text { Accessible online at: } \\
\text { www.karger.com/crd }\end{array}$
\end{tabular}


indications and outcomes of valve replacement for aortic valvular cardiomyopathy. Dr. Alexander Geha from the University of Illinois discusses the topic of mitral valve repair in patients with ischemic and nonischemic cardiomyopathy. The topic of myocardial revascularization in patients with ischemic cardiomyopathy and left ventricular dysfunction is discussed in two papers from Tufts University and the University of Illinois. In the first paper, Dr. Kamal Khabbaz and associates from Tufts-New England Medical Center discuss the pros and cons of beating heart versus on-pump coronary artery bypass grafting in patients with ischemic cardiomyopathy and viable myocardium. The second paper provides a summary of the clinical trials comparing coronary artery bypass grafting to percutaneous coronary interventions and medical therapy in patients with left ventricular dysfunction. Dr. Robert Michler and his group from Ohio State University summarize the different ongoing clinical trials in the surgical management of CHF. Dr. Patrick McCarthy and associates from the Cleveland Clinic provide a valuable update on their experience with ventricular reduction and remodeling surgery for $\mathrm{CHF}$. This special issue also provides an update on the current status of heart transplantation with alarming statistics about the limited utilization of this treatment option in developing and underdeveloped countries, and about the gender disparity among heart transplant recipients worldwide, with three quarters of the transplants performed in men. Dr. Bradley Knight and his associate from the University of Chicago provide an update on the current status of resynchronization therapy and biventricular pacing for CHF. From the same institution, Drs. Jai Raman and Val Jeevanandam update the reader on the use of left ventricular assist devices as destination therapy. Dr. Mehmet $\mathrm{Oz}$ and associates from Columbia University in New York provide a very interesting report on the use of assist devices as a bridge to transplant and to recovery. Dr. O. Howard Frazier and his group at the Texas Heart Institute update the reader on the clinical experience with the Jarvik 2000 left ventricular assist device for destination therapy and bridging to transplantation. Also, Dr. Frazier and his group along with Drs. Robert Dowling and Laman Gray from the University of Louisville provide a valuable update on the world's clinical experience, to date, with the AbioCor total artificial heart. On the genetic level, Dr. Chaer and associates discuss the biologic basis for gene manipulation therapy of premature coronary artery disease. Dr. Todd Rosengart and associates from Northwestern University provide an update on the current trials in gene therapy in their elegant paper entitled 'Therapeutic angiogenesis: a biologic bypass'. From the same institution, Dr. Keith Horvath talks about the current status and the future of transmyocardial laser revascularization for the ischemic myocardium with nonbypassable coronaries. Dr. Jeffery Platt and associates from the Mayo Clinic provide an intriguing update on the present status and the future of cardiac xenotransplantation.

We hope that this special issue will give the journal a new impact in the sense that it will acquaint the current readers and subscribers, who are primarily cardiologists, with these surgical alternatives for the management of $\mathrm{CHF}$ and at the same time bring into the journal readership a stronger surgical presence.

Malek G. Massad, MD

Guest Editor, Chicago, Ill.

\section{Reference}

1 Murdoch DR, McMurray JJV: Epidemiological perspective on heart failure: Common, costly, disabling, deadly; in Sharpe N (ed): Heart Failure Management. London, Martin Dunitz, 2000, pp 1-14. 